\title{
Driving transit retention to renaissance: Trends in Montreal commute public transport mode share and factors by age group and birth cohort
}

Michael Grimsrud $^{1}$ and Ahmed El-Geneidy ${ }^{1}$

(1) School of Urban Planning, McGill University, Suite 400, 815 Sherbrooke St. W., Montréal, QC H3A 2K6, Canada

Michael Grimsrud

E-mail: michael.grimsrud@mail.mcgill.ca

Ahmed El-Geneidy

E-mail: ahmed.elgeneidy@mcgill.ca

For citation please use: Grimsrud, M. \& El-Geneidy, A. (2013). Driving transit retention to renaissance: Trends in Montreal commute public transport mode share and factors by age group and birth cohort. Public transport: Planning and Operations, 5(3), 119-241.

\begin{abstract}
Public transport mode share for young people appears to be growing in the $21^{\text {st }}$ Century, and higher than previous mode shares appear likely to continue, increasing overall demand as today's youths age into traditionally lower public transport-use lifecycle stages. This paper tests and supports the latter claim through application of a number of binomial logistic regression models, controlling for socioeconomic, household composition, location and service level factors. Analysis draws from over 10,000 home-based work and school commute trips from each of Montreal's 1998, 2003, and 2008 origin-destination surveys. One large factor in Montreal's increased youth public transport usage has been the 1997 introduction of graduated driver's licensing, which appears to have a substantial lasting licensure damper effect only on men. Controlling for effects of variables other than survey period and age group or birth cohort, recent young age groups show higher public transport use than did their predecessors. Moreover, a plateauing of public transport mode share within birth cohorts is seen to begin earlier in life than expected. This suggests not only continuance of higher than previous transit use, but also further potential for mode share improvements if challenges from lifecycle changes, such as school-towork transition, can be identified and addressed.
\end{abstract}

Keywords: Public transport - mode share - logit - cohort - lifecycle - Montreal 


\section{1 - INTRODUCTION}

Not only is public transport ridership growing and automobile use declining among young people in places such as the US (Davis, Dutzik, \& Baxandall, 2012) and Germany (Kuhnimhof, Buehler, Wirtz, \& Kalinowska, 2012), but also it appears that much of this change is likely to hold as currently young people progress through lifecycle changes (Grimsrud \& El-Geneidy, 2013). Grimsrud and El-Geneidy (2013) examine commute mode share of birth cohorts in Greater Montreal, Canada from 1998 to 2008. They found a general pattern of decreasing public transport (hereafter interchangeably termed "transit”) mode share with age until a long plateau is reached at about the early 30s. They also document increasing transit use among young people of similar ages between successive survey years, who continue to reduce use as they age, but to a substantially higher plateau than that of former aging youth, which suggests that policy aimed at establishing transit habits early in life can lead to overall ridership gains.

Grimsrud and El-Geneidy’s (2013) analysis is somewhat limited, however - while it does include comparisons of trends for different household and rough home location groups, it is mainly based on summary statistics and does not simultaneously control for other important variables. Observed mode share changes could in fact be responses to unmeasured changes in level of service, home or destination locations relative to network features, work versus school trips or other factors - developments that might not continue along the same trajectory. They also observe an upswing in transit use among older cohorts in 2008, contrary to the plateau thesis, that they suggest reflects somewhat temporary effects of a gasoline price spike, but that conversely might result from service level or other physical changes - or indicate mode choiceinfluencing evolution of values even among mature commuters. 
This paper examines 1998, 2003, and 2008 Montreal home-based work and school commute mode share, now constrained to trips beginning and ending on the Island of Montreal, on which historical network information is available for inclusion as control variables in binary logistic regression models. It asks whether commute transit mode share has increased for people aged 20-34, whether birth cohorts show stable mode shares through their 30s-50s, whether any observed 2008 transit use spike can be explained by service level and other tested factors, and whether there are noteworthy differences or trends between age groups and years in factors that influence transit mode share. If the first two questions test positively, it will support Grimsrud and El-Geneidy's (2013) calls for further policy targeting youths and increased overall transit provision to meet expected future demand. The third and fourth questions aim to enrich understanding of potentially uneven and evolving relationships between groups' mode choices and underlying factors.

This paper is structured as follows: Sections 2 and 3 introduce pertinent literature and study context; section 4 describes the data, methodology and variables included in models and analysis as well as summary statistics; section 5 presents analysis results; and the paper concludes with policy implications and future research directions.

\section{2 - LITERATURE REVIEW}

While a number of studies examine mode share or automobile ownership, a common proxy, by age group in different years (Beige, 2008; Bush, 2005; Dargay, 2007; Matas \& Raymond, 2008; Thakuriah, Menchu, \& Tang, 2010), most find recent automobile increases among young adults. 
Dargay and Hanly (2007) and Thakuriah et al. (2010), find car ownership rising as increasing incomes and decreasing purchase prices outweigh modest changes in gasoline price, the latter authors additionally citing effects of suburbanization, a commonplace phenomenon over the past decades. Few studies, however, use recent enough data to speak to current trends introduced by Davis et al. (2012) and Kuhnimhof et al. (2012). Beige (2008), using stratified 1985-2004 Zurich region longitudinal data, shows that people of the same age born more recently generally own more cars than those born earlier; conversely, the youngest male group, born 1980-89, owns substantially fewer at the same age as those born 1970-79. Emerging evidence that young people might be starting to drive less than previous generations, however, does not guarantee the same choices later in life.

Transport mode choice inertia does make some intuitive sense. Automobiles have large sunk costs that can dwarf those of individual trips. Transit passes can be seen similarly to some degree. Changing modes also might require learning new routes or procedures, as well as overcoming perceived threats or inconveniences. More generally, preferences and habits that form in young adulthood or earlier are thought to hold through life (Bush, 2005). Habit is one of the factors most consistently found significant in a systematic review of 76 mode choice papers (De Witte, Hollevoet, Dobruszkes, Hubert, \& Macharis, 2013), but is rarely studied (De Witte et al., 2013; Simma \& Axhausen, 2003; Thogersen, 2006), owing perhaps to the frequent use of cross-sectional study designs (Thogersen, 2006).

Some studies, using repeated cross-sectional, panel, or retrospective survey designs, have examined mode choice or automobile ownership changes among individuals, households, or 
groups (Dargay \& Hanly, 2003; Matas \& Raymond, 2008; Nolan, 2010; Simma \& Axhausen, 2003; Thakuriah et al., 2010). Dargay and Hanly (2003) find mode changes to occur with almost three times the average frequency when both home and work locations also change. Beige (2008) finds both moves and mobility tool changes to be heavily concentrated between the ages of 20 and 35. Household structure changes like coupling and having children can also impact mode choice, affecting time and money availability and home feature priorities including moderelevant location. Thakuriah, Tang and Menchu (2009) show these changes occurring mostly between the ages of $18-24$ in the US, during which time about $50 \%$ of people move out from their parents' homes, 33\% marry, and 30\% have children. With relatively late onset as well as high upfront cost, automobile use is particularly consistent once begun (Beige, 2008; Dargay \& Hanly, 2003, 2007; Simma \& Axhausen, 2003). Beige (2008), using individual-level data rather than the more typical household-level data indexed by head-of-household age (which can misattribute effects of maturing children), shows fairly stable car ownership from about age 35 to 55.

A rough life-course automobile use trend appears from the literature to include a rise with increased income and responsibilities during a period of major life changes and flexible tastes, perhaps into the 30s, followed by a long plateau and slow decline later in life. Transit being the main competing mode at most distances, at least in bicycle-resistant North America, its use trend is presumably opposite. If higher than previous youth transit rates hold as birth cohorts enter the plateau years, if there is such a mode choice plateau, it is reasonable to expect rates to remain high, provided high rates are not merely responses to temporary contextual conditions. 


\section{3 - STUDY CONTEXT}

Montreal is Canada's second-largest city, with a modestly growing 2011 island population (including the city proper and several small nearby municipalities) of 1,886,481 (Statistics Canada, 2013). At 3,779.1 people per square kilometer, (Statistics Canada, 2013), it has high population density by North American standards and a relatively extensive transit network as seen in Figure 1. Developments that occurred between or near survey periods that likely affected morning peak commute mode choice include graduated drivers' licensing introduction in 1997 (Simpson, 2003), student transit fare reduction for 18-25-year-olds in 2002, added bus routes, and perhaps smart card introduction in 2008 (Societe de transport de Montreal (STM), 2012). However, regional home ownership increased from 48.6\% in 1996 to 53.4\% in 2006 (Statistics Canada, 2010) and regional unemployment decreased (9.7\% 1998, 9.5\% 2003, 7.4\% 2008) (Statistics Canada, 2012a), potentially favoring car usage.

Average transit prices for the province increased by a higher percentage between study periods than did automobile use prices (Statistics Canada, 2012b), but less in absolute terms, and gasoline prices spiked to nearly $\$ 1.50$ per liter shortly before the 2008 survey (Regie de l'energie Quebec, 2009), perhaps affecting commuting habits. Similar to trends elsewhere in North America after gasoline settled, October 2009 total transit ridership in Montreal was 2\% lower than October 2008’s (Dickens, 2012). 

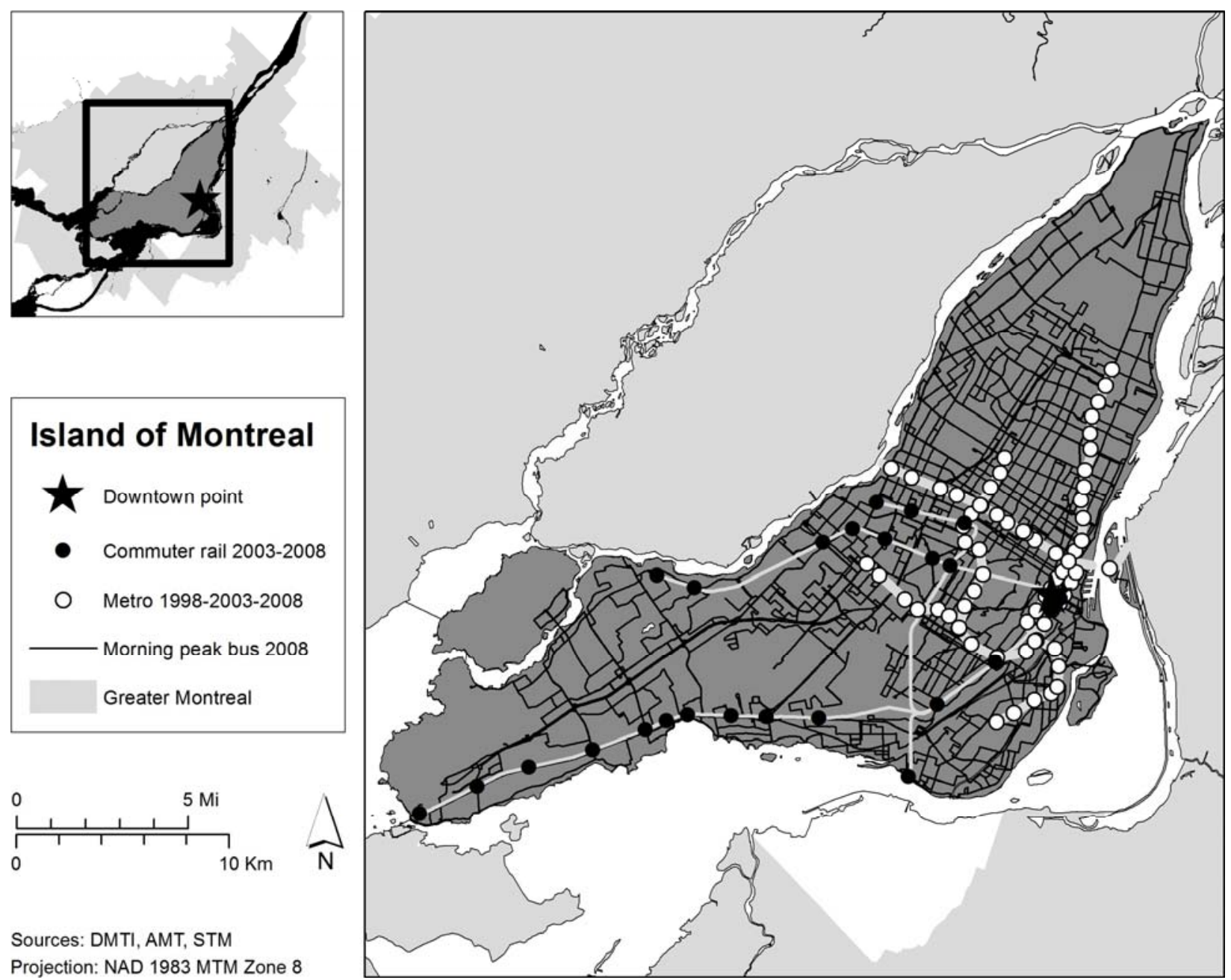

Sources: DMTI, AMT, STM

Projection: NAD 1983 MTM Zone 8

Figure 1: Island of Montreal context

\section{4 - DATA AND METHODOLOGY}

Initial analysis involved inspecting changes in summary statistics, followed by testing for significant differences in transit (versus automobile) mode share between five-year age groups in each survey year, using a binary logistic regression model that controlled for variables listed below. Additional modeling is also performed and introduced at the end of this section.

The primary data sources for this study are 1998, 2003, and 2008 Montreal region O-D surveys, conducted by telephone in the fall of each year by a group of local transportation authorities, 
sampling approximately 5\% of region residents (Agence Metropolitaine de Transport (AMT), 2012a). From over 300,000 trips per year, Grimsrud and El-Geneidy (2013) included 53,739 45,049 per year, after standardizing the area boundary between years, and keeping only home-towork and home-to-school commutes by those aged 20-59. This study further filters cases to those beginning and ending on the Island of Montreal (outside of which historical bus route data was unavailable), beginning during the 6:30 to 9:30 am peak (Diab \& El-Geneidy, 2012), and includes a maximum of one randomly chosen trip per household, for a total of 37,523 trips. Trips from census tracts for which income figures could not be determined, that caused unresolved transport network modeling errors, or that involved persons with unclear driver's licensure status, were also excluded, yielding 37,114 trips. To improve model fit, trips involving neither transit nor automobiles, those involving both, and those involving interregional modes, taxi cabs etcetera, were also excluded, for a usable sample of 32,189 home-based commute trips. Tangentially, walk- or cycle-only trips increased from 9-11\% from 1998-2008, car-plus-transit trips increased from 2-3\%, both trends fairly linear, and other trips stayed under $1 \%$. Summary statistics of included observations are given in Tables 1 and 2 after discussions of variables summarized on each table.

Use of transit, as opposed to automobile, is the dependent variable for all logit models in this study, and is measured at the individual trip level. The primary explanatory variables of interest are those capturing changes in time and with age and aging, to which socioeconomic, trip, public transit level of service and location control covariates are added. Effort was made to generate a wide variety of potential control variables, and to represent as many distinct themes as possible that are frequently found important in the literature. Variables with high to medium correlations 
were then dropped from sets based on a correlation matrix generated for all variables with one exception mentioned below. Inclusion decisions were based primarily on strength of bivariate relationship to mode choice, logical and literature-supported fit, and frequency of overcorrelation with other variables. Control covariates found insignificant at the $95 \%$ confidence interval level in the main model were removed from all models, but those found insignificant only in restricted membership models, introduced at the end of this section, were allowed to remain to facilitate inter-model comparisons. Age group/period variables in the main model were similarly kept regardless of tested significance to allow inter-variable comparisons.

\section{Age, cohort, period}

Twenty-four dummy variables were generated, one for each possible combination of eight fiveyear age groups and three survey periods. The other twenty-three were compared to the 1998 5559-year-old reference group. This produced the same model power as using separate sets of seven (plus reference) age groups and two (plus reference) survey periods. Age-period-cohort time variables suffer from perfect linearity and cannot easily be modeled together (Mason, Mason, Winsborough, \& Poole, 1973). Here, the twenty-three other age group/cohort/period points are first left as such and directly compared to the reference group, to give an initial impression of the dataset before breaking it into separately examined age and cohort groups outlined at the end of this section. Theoretically, age, period, and cohort effects can be meaningfully examined together in a single model if one substitutes one or more other continuous variables for age, period, or cohort groups (Bush, 2005; O'Brien, 2000), but if said variable(s) inadequately represent variation at the substituted time scale, the problem of misattribution remains. Lacking sufficiently comprehensive data and knowledge of the survey 
region, and suspecting that important but otherwise unmeasured influences are present at each time scale, a choice was made to separately examine, test, and compare apparent age group and cohort trends.

\section{Socioeconomic variables}

Gender is commonly included in mode share studies. While De Witte et al. (2013) find it to be significant in less than half of these, females show substantially and consistently higher transit use in Greater Montreal than males in all survey periods (Grimsrud \& El-Geneidy, 2013), and likely behave similarly in the constituent Island of Montreal study region. School trips were found by Kim and Ulfarsson (2008), controlling for age and other factors, to be significantly more likely than work trips to use transit, and the same is expected in Montreal, where the 20-24year-old student population exceeds that of workers. Similarly, driver's licensure is a legal prerequisite to driving, so its absence is expected to have a sizeable positive effect on transit use, as indicated by Cervero and Kockelman (1997). However, even after limiting analysis to car vs. transit users, a proportion of commuters with licenses are expected to take transit and some without licenses are expected to carpool.

At the household level, number of automobiles per licensed driver is logically more telling than similar measures like cars per adult as used by Sweet \& Chen (2011). It has slightly less bivariate correlation with transit use here than does household car count, but the latter distorts household population variable effects. Children add responsibilities for at least some adult household members and are expected to reduce available time, often favoring automobiles over transit. Trip chaining, notably including taking children to school, is beyond the scope of this study, and thus 
the effects of children are undoubtedly downplayed here. Nonetheless, and while older children are too strongly correlated with other control variables for inclusion, the presence of children younger than five years old is expected to have an independent negative effect on transit use as seen elsewhere (Cervero \& Kockelman, 1997). The number of household commuters (as defined by sample inclusion criteria) is also expected to negatively relate to transit use, again relating to the wider region findings of Grimsrud and El-Geneidy (2013). After accounting for location and automobile access variables, remaining correlation might reflect carpool potential.

While this study attempts to minimize data aggregation, an exception is made for average income of individuals aged 15 and over per census tract (inflation-adjusted to 2013 Canadian dollars). Of variables included in over a fifth of mode choice studies, income is the second-most consistently found significant (after car availability) (De Witte et al., 2013), but such information is not available in the 1998 Origin-Destination (O-D) survey, so census tract income data was used in lieu (Statistics Canada, 2012c). Approximations for each year were derived assuming constant annual growth rates based on the nearest two available of the 1996, 2001, and 2006 census years. Trips from census tracts without two income reference years were excluded from analysis. 
Table 1: Descriptive statistics 1

\begin{tabular}{|c|c|c|c|c|c|c|c|c|c|c|c|}
\hline \multirow[b]{2}{*}{ Age } & \multirow[b]{2}{*}{ Year } & \multirow[b]{2}{*}{$\mathbf{n}$} & \multirow[b]{2}{*}{$\begin{array}{c}\text { Survey } \\
\text { share }\end{array}$} & \multirow[b]{2}{*}{$\begin{array}{c}\text { Transit } \\
\text { use }\end{array}$} & \multicolumn{3}{|c|}{ Dummy } & \multicolumn{3}{|c|}{ Household } & \multirow{2}{*}{$\begin{array}{c}\text { Census tract } \\
\text { Income } \\
\end{array}$} \\
\hline & & & & & Female & $\begin{array}{c}\text { School } \\
\text { trip }\end{array}$ & $\begin{array}{c}\text { No } \\
\text { license }\end{array}$ & $\begin{array}{c}\text { Cars per } \\
\text { license }\end{array}$ & $\begin{array}{c}\text { Children } \\
<5\end{array}$ & Commuters & \\
\hline \multirow[t]{3}{*}{$20-24$} & 1998 & 1556 & $13.17 \%$ & $61.89 \%$ & $52.19 \%$ & $47.81 \%$ & $25.32 \%$ & 0.53 & 0.04 & 2.19 & $\$ 33,468.87$ \\
\hline & 2003 & 1305 & $12.65 \%$ & $70.57 \%$ & $57.01 \%$ & $52.72 \%$ & $32.95 \%$ & 0.51 & 0.04 & 2.21 & $\$ 34,924.55$ \\
\hline & 2008 & 918 & $9.13 \%$ & $72.22 \%$ & $54.90 \%$ & $58.71 \%$ & $33.99 \%$ & 0.58 & 0.04 & 2.39 & $\$ 38,478.22$ \\
\hline \multirow[t]{3}{*}{$25-29$} & 1998 & 1571 & $13.30 \%$ & $41.57 \%$ & $51.56 \%$ & $14.45 \%$ & $15.72 \%$ & 0.67 & 0.18 & 1.80 & $\$ 33,708.11$ \\
\hline & 2003 & 1536 & $14.89 \%$ & $49.67 \%$ & $51.50 \%$ & $16.41 \%$ & $17.64 \%$ & 0.61 & 0.13 & 1.82 & $\$ 34,518.35$ \\
\hline & 2008 & 1176 & $11.69 \%$ & $61.99 \%$ & $53.40 \%$ & $17.26 \%$ & $21.09 \%$ & 0.58 & 0.12 & 1.95 & $\$ 35,152.58$ \\
\hline \multirow[t]{3}{*}{$30-34$} & 1998 & 1706 & $14.44 \%$ & $35.87 \%$ & $46.42 \%$ & $7.03 \%$ & $12.19 \%$ & 0.71 & 0.36 & 1.67 & $\$ 35,302.21$ \\
\hline & 2003 & 1296 & $12.56 \%$ & $39.66 \%$ & $46.84 \%$ & $8.95 \%$ & $15.74 \%$ & 0.69 & 0.33 & 1.63 & $\$ 36,103.50$ \\
\hline & 2008 & 1282 & $12.75 \%$ & $50.08 \%$ & $46.65 \%$ & $11.08 \%$ & $15.52 \%$ & 0.65 & 0.34 & 1.73 & $\$ 36,465.97$ \\
\hline \multirow[t]{3}{*}{$35-39$} & 1998 & 1838 & $15.56 \%$ & $33.19 \%$ & $47.66 \%$ & $4.79 \%$ & $12.13 \%$ & 0.75 & 0.32 & 1.60 & $\$ 36,606.54$ \\
\hline & 2003 & 1376 & $13.34 \%$ & $34.30 \%$ & $48.91 \%$ & $6.25 \%$ & $14.03 \%$ & 0.73 & 0.27 & 1.61 & $\$ 37,740.60$ \\
\hline & 2008 & 1243 & $12.36 \%$ & $45.78 \%$ & $50.84 \%$ & $6.28 \%$ & $14.16 \%$ & 0.73 & 0.37 & 1.66 & $\$ 38,475.28$ \\
\hline \multirow[t]{3}{*}{$40-44$} & 1998 & 1825 & $15.45 \%$ & $32.38 \%$ & $51.95 \%$ & $3.67 \%$ & $12.82 \%$ & 0.71 & 0.13 & 1.65 & $\$ 37,278.77$ \\
\hline & 2003 & 1497 & $14.51 \%$ & $32.00 \%$ & $51.30 \%$ & $4.28 \%$ & $11.29 \%$ & 0.76 & 0.16 & 1.64 & $\$ 39,039.73$ \\
\hline & 2008 & 1442 & $14.34 \%$ & $37.59 \%$ & $54.92 \%$ & $4.85 \%$ & $10.89 \%$ & 0.76 & 0.18 & 1.68 & $\$ 39,804.75$ \\
\hline \multirow[t]{3}{*}{$45-49$} & 1998 & 1459 & $12.35 \%$ & $32.21 \%$ & $50.72 \%$ & $2.60 \%$ & $12.61 \%$ & 0.70 & 0.04 & 1.78 & $\$ 37,912.42$ \\
\hline & 2003 & 1387 & $13.44 \%$ & $30.43 \%$ & $53.50 \%$ & $2.24 \%$ & $11.75 \%$ & 0.75 & 0.05 & 1.75 & $\$ 39,775.72$ \\
\hline & 2008 & 1506 & $14.97 \%$ & $34.99 \%$ & $54.45 \%$ & $1.66 \%$ & $10.16 \%$ & 0.75 & 0.05 & 1.74 & $\$ 41,063.56$ \\
\hline \multirow[t]{3}{*}{$50-54$} & 1998 & 1219 & $10.32 \%$ & $28.06 \%$ & $52.58 \%$ & $1.39 \%$ & $12.55 \%$ & 0.73 & 0.01 & 1.82 & $\$ 39,780.51$ \\
\hline & 2003 & 1185 & $11.48 \%$ & $31.14 \%$ & $57.22 \%$ & $0.76 \%$ & $12.24 \%$ & 0.73 & 0.02 & 1.83 & $\$ 40,802.45$ \\
\hline & 2008 & 1503 & $14.94 \%$ & $39.92 \%$ & $57.09 \%$ & $1.00 \%$ & $13.84 \%$ & 0.72 & 0.02 & 1.81 & $\$ 40,705.49$ \\
\hline \multirow[t]{3}{*}{$55-59$} & 1998 & 640 & $5.42 \%$ & $25.31 \%$ & $47.19 \%$ & $0.94 \%$ & $10.31 \%$ & 0.76 & 0.01 & 1.67 & $\$ 39,604.79$ \\
\hline & 2003 & 736 & $7.13 \%$ & $28.13 \%$ & $54.08 \%$ & $1.22 \%$ & $10.33 \%$ & 0.74 & 0.00 & 1.71 & $\$ 41,963.14$ \\
\hline & 2008 & 987 & $9.81 \%$ & $38.70 \%$ & $58.26 \%$ & $0.91 \%$ & $14.39 \%$ & 0.69 & 0.01 & 1.66 & $\$ 41,749.71$ \\
\hline \multirow[t]{3}{*}{ Total } & 1998 & 11814 & $100.00 \%$ & $37.27 \%$ & $50.12 \%$ & $11.06 \%$ & $14.47 \%$ & 0.69 & 0.16 & 1.77 & $\$ 36,374.54$ \\
\hline & 2003 & 10318 & $100.00 \%$ & $40.19 \%$ & $52.35 \%$ & $12.16 \%$ & $16.00 \%$ & 0.69 & 0.13 & 1.78 & $\$ 37,814.02$ \\
\hline & 2008 & 10057 & $100.00 \%$ & $46.28 \%$ & $53.76 \%$ & $10.75 \%$ & $15.86 \%$ & 0.69 & 0.14 & 1.81 & $\$ 39,063.74$ \\
\hline
\end{tabular}


Table 1 summarizes survey and mode share and socioeconomic variables by age group and survey year. Values significantly different (95\% CL) in 1998 or 2008 from 2003 are marked in bold for within age groups and in italics for within birth cohorts. Transit morning peak commute mode share increased over both intervals between surveys, from a low of $37.27 \%$ to a high of 46.28\%, despite lower-use older groups constituting increasing sample shares. Most of the growth between 1998 and 2003 was from individuals in their early 30s and younger, while 2008 figures reflected growth for all age groups. Females steadily increased in sample share, from near parity to over 53\%. School (versus work) commutes became increasingly popular among younger age groups, but declined overall in 2008 as older groups increased in size. Increases in share of people without licenses, similarly, are seen in young groups but less so overall.

Large licensure drops are evident for those in their early 20s in 2003 and to a lesser extent those in their late 20s in 2008. This suggests that some damper effects from the 1997 graduated licensure introduction (which would not have applied to many already in their 20s in 1998) last through lifecycle changes. Not pictured, this second licensure drop is almost exclusively male. For men, who at most age groups and years show approximately $10 \%$ higher licensure rates than women, reduction seems to be holding, while women's already relatively low rates seem only to be temporarily affected. In $2008,19.5 \%$ of men and $22.5 \%$ of women in their late 20 s reported having no license, compared to $12.8 \%$ and $22.3 \%$ in 2003.

Household variables, including numbers of cars per licensed driver, of young children, and of commuters, do not show dramatic overall changes, but the average number of young children appears to have dropped among people in their late 20s by 2003 and stayed down in 2008, 
possibly facilitating transit use. Small, sometimes significant increases in the average number of commuters per household and in income figures are seen for most age groups over both periods.

\section{Trip, level of service and location}

Trip times were estimated for each pair of origins and destinations using multimodal networks assembled by the researcher (walk, bus, metro, commuter rail). A fastest route, using whichever combination of the aforementioned modes yielded the minimum time, was calculated for each pair in ArcGIS. Best route selection did not include waiting and transfer times, due to data limitations discussed below, but the resulting trip time variable nonetheless correlated more strongly with transit use than did road network distance, and the trip time calculation method was the same for the entire dataset.

The street network on the Island of Montreal was assumed not to have changed substantially between survey periods, but traffic speeds were assumed to have changed, so lacking detailed historical traffic information, driving time was not included as a variable. This unfortunately precluded drive versus transit time comparisons as used by Limtanakool and Djist (2006) or Shalaby (1998). Transit network times are expected to show some negative correlation with transit use, as automobiles can often offer faster, more direct access for peripheral areas far from major employment hubs. Walking speed was input as $5 \mathrm{~km} / \mathrm{hr}$, slightly lower than average walking speed for non-senior adults (Knoblauch, Pietrucha, \& Nizburg, 1996), to account for intersection delays. No new metro stations appeared on the island during either interval, but one commuter rail line was added in 2001 (Agence Metropolitaine de Transport (AMT), 2012b). Commuter train trip times were taken from official schedules, averaging each direction's 
morning peak hours total time over the length of track in the study region and deriving speeds and times for each possible leg. Metro times were similarly calculated, but based on averages of each direction's first and last morning peak period train given in Google Maps. Metro and commuter train speeds were assumed not to have changed significantly between survey periods, being separated from the road network.

Historical bus route locations and times were estimated using September schedules for each survey year supplied by Societe de transport de Montréal (STM), the transit authority serving the Island of Montreal, filtered only to include routes operating during the morning peak period; and a 2007 STM bus route shapefile. These schedules only offer departure times from a small and changing selection of stops per route (often 4-6), and full historical stop location information was unavailable. Bus access and egress was thus modeled to be possible at all route-street intersections - while this brings some inaccuracy, bus stops are frequent in Montreal so there should be minimal impact on results and effects from this error are not expected to differ significantly between age groups or survey periods. Routes were assumed not to have changed course between years if schedules listed similar stop location names on schedules (although later years tended to name a larger share of points per route). Routes not shown on the shapefile were drawn in, with all named points located using Google Maps. Routes not listed for a previous time period were removed from its shapefile. Google Maps automobile and public transport directions were used to estimate connecting paths between points, mimicking current routes between like points and/or minimizing road travel time and route complexity as appropriate. Without precise stop times and locations for each year, it was not possible to determine trip wait and transfer times for inclusion in networks. Bus speed was calculated the same way as commuter rail speed. 
Destinations were examined, as well as home locations, as they might often play a larger role in mode choice (Chen, Gong, \& Paaswell, 2008; Limtanakool \& Dijst, 2006), and variables were kept commensurate between the two location types to allow direct comparison.

Distance to downtown $(\mathrm{km})$, defined as the intersection of St. Catherine Street and McGill College Avenue, was measured from each location using the street network, with both home and work/school distances expected to significantly and negatively correlate with transit use. Other location variables thought pertinent to mode choice were calculated using 500 Euclidian meter buffers around each home and destination. Network distance buffers might be preferable, but are more difficult to compute for such a large dataset. The 500m buffers approximate 600 network meters (Levinson \& El-Geneidy, 2009), a larger boundary than traditionally used, but one thought to more accurately describe user sensibilities in Montreal, where the $85^{\text {th }}$ percentile of distances walked to bus stops was found to be $550 \mathrm{~m}$ and $660 \mathrm{~m}$ to homes and destinations, respectively (El-Geneidy, Tetreault, \& Surprenant-Legault, 2010).

Average bus wait times for nearby buses during peak periods were calculated for each home and destination location by halving headway for more frequent routes and assigning '8 minutes' for those with headways exceeding 15 minutes. There is variety among users (Fan \& Machemehl, 2009), but after about 15 minutes headway, users often consult schedules and not just show up at bus stops to wait on average half the headway time (Hall, 2001). Average wait time of nearby buses, while not as precise as wait time of buses actually used in a trip, acts as its surrogate, while also suggesting neighborhood demand and density, often found significant in mode choice (De Witte et al., 2013). Increased wait time is expected to correspond to decreased transit use. 
Nearby home and destination bus route count, metro stop count and commuter rail stop count similarly indicate level of service and neighborhood character. Destination metro count and distance to downtown constitute the only pair of variables kept that exceed 50\% correlation ($60 \%$ ). While metro stations are not found extremely far from downtown, many places without nearby metro stations are more central than others with, and the two variables are conceptually distinct. All route and station count variables are expected to vary positively with transit use, perhaps with destination variables exerting more influence than their home counterparts.

Table 2 summarizes trip, level of service and location variables. Average travel time differs little between age groups or years. Average distance to downtown, both from home and from work/school, has decreased over both intervals overall and for many groups, contrary to the wider regional trend (Collin, Dagenais, \& Poitras, 2003). Similarly, nearby bus route and metro stop counts have increased from 1998 to 2003 and from 2003 to 2008, though not significantly for metro in 2008. With no new metro stops built on the Island of Montreal, growth figures indicate some increased housing density near existing metro stations. Age-specific figures show younger groups' homes and destinations especially close to metro stations, although homes less so for 2008's youngest, possibly reflecting rising prices. Bus routes were added, however, with 285 morning peak routes in 1998, 306 in 2003, and 320 in 2008 derived from STM schedules (2013). Average wait time is the single variable type on this chart showing overall change likely undesirable for transit use. As with income, service and location variable changes are gradual, spread fairly equally between the two intervals, and do not offer explanations for the populationwide jump in transit use in 2008 seen on Table 1. 
Table 2: Descriptive statistics 2

\begin{tabular}{|c|c|c|c|c|c|c|c|c|c|c|c|c|}
\hline \multirow[b]{2}{*}{ Age } & \multirow[b]{2}{*}{ Year } & \multirow{2}{*}{$\begin{array}{c}\text { Travel } \\
\text { time hr }\end{array}$} & \multicolumn{2}{|c|}{ To downtown km } & \multicolumn{2}{|c|}{ Bus route count } & \multicolumn{2}{|c|}{ Average bus wait min } & \multicolumn{2}{|c|}{ Metro stop count } & \multicolumn{2}{|c|}{ Commuter rail stop } \\
\hline & & & Home & Destination & Home & Destination & Home & Destination & Home & Destination & Home & Destination \\
\hline \multirow[t]{3}{*}{$20-24$} & 1998 & 0.44 & 10.30 & 6.96 & 8.47 & 10.33 & 6.25 & 6.19 & 0.37 & 1.01 & 0.04 & 0.09 \\
\hline & 2003 & 0.43 & 9.82 & 6.20 & 8.70 & 11.13 & 6.37 & 6.21 & 0.37 & 1.12 & 0.04 & 0.09 \\
\hline & 2008 & 0.47 & 11.21 & 6.35 & 8.68 & 12.33 & 6.64 & 6.47 & 0.29 & 1.10 & 0.04 & 0.09 \\
\hline \multirow[t]{3}{*}{$25-29$} & 1998 & 0.44 & 10.20 & 7.97 & 8.53 & 10.18 & 6.20 & 6.34 & 0.29 & 0.81 & 0.05 & 0.13 \\
\hline & 2003 & 0.44 & 9.65 & 7.14 & 8.55 & 11.30 & 6.43 & 6.36 & 0.35 & 0.91 & 0.04 & 0.13 \\
\hline & 2008 & 0.42 & 9.20 & 6.58 & 9.47 & 12.61 & 6.57 & 6.59 & 0.40 & 1.02 & 0.03 & 0.13 \\
\hline \multirow[t]{3}{*}{$30-34$} & 1998 & 0.46 & 11.22 & 7.95 & 8.22 & 10.21 & 6.26 & 6.33 & 0.27 & 0.77 & 0.04 & 0.16 \\
\hline & 2003 & 0.46 & 10.50 & 7.63 & 8.72 & 11.49 & 6.41 & 6.49 & 0.30 & 0.77 & 0.05 & 0.13 \\
\hline & 2008 & 0.44 & 9.45 & 6.80 & 9.10 & 12.60 & 6.57 & 6.65 & 0.31 & 0.91 & 0.04 & 0.13 \\
\hline \multirow[t]{3}{*}{$35-39$} & 1998 & 0.47 & 12.12 & 8.37 & 7.57 & 10.24 & 6.29 & 6.37 & 0.20 & 0.74 & 0.04 & 0.14 \\
\hline & 2003 & 0.48 & 11.80 & 7.78 & 7.93 & 11.53 & 6.53 & 6.49 & 0.24 & 0.79 & 0.05 & 0.15 \\
\hline & 2008 & 0.45 & 10.22 & 7.43 & 8.78 & 12.67 & 6.59 & 6.65 & 0.28 & 0.84 & 0.04 & 0.16 \\
\hline \multirow[t]{3}{*}{$40-44$} & 1998 & 0.49 & 12.82 & 8.39 & 7.56 & 10.02 & 6.39 & 6.35 & 0.19 & 0.74 & 0.05 & 0.13 \\
\hline & 2003 & 0.47 & 12.54 & 8.27 & 7.55 & 11.27 & 6.55 & 6.49 & 0.21 & 0.80 & 0.04 & 0.13 \\
\hline & 2008 & 0.47 & 11.55 & 8.07 & 8.56 & 12.35 & 6.68 & 6.69 & 0.23 & 0.80 & 0.05 & 0.13 \\
\hline \multirow[t]{3}{*}{$45-49$} & 1998 & 0.47 & 12.17 & 8.03 & 7.70 & 9.95 & 6.33 & 6.25 & 0.21 & 0.76 & 0.04 & 0.14 \\
\hline & 2003 & 0.47 & 12.71 & 8.08 & 7.59 & 11.48 & 6.60 & 6.49 & 0.21 & 0.80 & 0.04 & 0.13 \\
\hline & 2008 & 0.47 & 12.02 & 7.97 & 8.29 & 12.44 & 6.75 & 6.69 & 0.20 & 0.74 & 0.04 & 0.15 \\
\hline \multirow[t]{3}{*}{$50-54$} & 1998 & 0.45 & 12.47 & 8.59 & 7.45 & 9.93 & 6.35 & 6.30 & 0.18 & 0.69 & 0.03 & 0.13 \\
\hline & 2003 & 0.46 & 12.05 & 8.03 & 7.81 & 11.23 & 6.60 & 6.44 & 0.23 & 0.82 & 0.03 & 0.13 \\
\hline & 2008 & 0.47 & 11.57 & 7.46 & 8.37 & 12.48 & 6.73 & 6.68 & 0.23 & 0.86 & 0.03 & 0.14 \\
\hline \multirow[t]{3}{*}{$55-59$} & 1998 & 0.44 & 12.64 & 8.80 & 7.25 & 9.77 & 6.33 & 6.26 & 0.16 & 0.68 & 0.05 & 0.12 \\
\hline & 2003 & 0.45 & 12.47 & 8.61 & 7.81 & 11.12 & 6.54 & 6.45 & 0.17 & 0.70 & 0.05 & 0.12 \\
\hline & 2008 & 0.46 & 11.62 & 7.73 & 8.27 & 12.44 & 6.75 & 6.67 & 0.22 & 0.81 & 0.04 & 0.14 \\
\hline \multirow[t]{3}{*}{ Total } & 1998 & 0.46 & 11.67 & 8.08 & 7.89 & 10.11 & 6.30 & 6.31 & 0.24 & 0.78 & 0.04 & 0.13 \\
\hline & 2003 & 0.46 & 11.37 & 7.67 & 8.10 & 11.33 & 6.50 & 6.43 & 0.26 & 0.85 & 0.04 & 0.13 \\
\hline & 2008 & 0.46 & 10.89 & 7.36 & 8.68 & 12.49 & 6.66 & 6.64 & 0.27 & 0.87 & 0.04 & 0.14 \\
\hline
\end{tabular}




\section{Untested}

Conspicuously absent are price, parking, and socio-psychological variables. Exact prices paid for transit by Montrealers cannot be determined from O-D survey data due to multiple fare type options. Moreover, for the vast majority of the system (excluding commuter rail) prices are spatially invariant so price differences would correlate too perfectly to survey period. Similarly, without date of interview data, gasoline price numbers would be the same for all participants in a given year and effects could not be distinguished from other period effects. Pricing information must then been excluded despite the potentially strong influence of a 2008 gasoline price spike. Parking availability and price data were not readily available but could theoretically improve models. Individuals’ perceptions, experiences, habits etcetera cannot be determined from the OD surveys used but are thought to be highly important mode choice determinants as outlined in the literature review section.

\section{Additional models}

To more precisely test trends within the eight age groups and eight birth cohorts (appearing in more than one survey) over time, 16 additional logit models were constructed with the same control variables. Transit ridership for each age group/period set was predicted in Stata for each dummy variable combination (eg. male student with no driver’s license), using mean continuous variable values of each age group/period. Predictions were compiled into a single predicted transit use chart in Microsoft Excel, weighing dummy combinations by their relative representation at each age group/period. Investigating a patterned discrepancy between actual and predicted values, 24 additional logit models - one for each age group/period - were constructed and examined to compare control variable effects between age group/periods. 


\section{5 - ANALYSIS}

Table 3 shows results from the full commute transit mode share logit model, including all age group/period combinations. All control variables are significant at the $99 \%$ confidence level and nearly all show the expected signs. The exception is travel time - it has a negative bivariate correlation with transit use, but is positively related after accounting for other factors, and might reflect distance-invariant transit price versus distance-variant automobile fuel cost. While significant, its effect was slight enough that the modeled unit had to be hours, rather than minutes, to produce a useful odds ratio. Not having a driver's license and automobile count per licensed driver show the greatest impacts, with odds ratios of 14.66 and 0.06 respectively.

Table 3: Full commute transit mode share logit model

\begin{tabular}{|c|c|c|c|c|}
\hline Parameter & & Coefficient & t-stat & Odds ratio \\
\hline \multirow[t]{3}{*}{ Dummy: } & Female & $0.28 * * *$ & 8.51 & 1.32 \\
\hline & School trip & $0.82 * * *$ & 13.69 & 2.27 \\
\hline & No license & $2.69 * * *$ & 46.48 & 14.66 \\
\hline \multirow[t]{3}{*}{ Household: } & Cars per license & $-2.89 * * *$ & -60.08 & 0.06 \\
\hline & Children $<5$ & $-0.22 * * *$ & -5.42 & 0.80 \\
\hline & Commuters & $-0.18 * * *$ & -7.78 & 0.84 \\
\hline Census tract: & Income (000 CAD) & $-0.01 * * *$ & -11.61 & 0.99 \\
\hline Modeled trip: & Travel time (hr) & $0.33 * * *$ & 3.71 & 1.39 \\
\hline \multirow[t]{5}{*}{ Home: } & Distance to downtown (km) & $-0.02 * * *$ & -4.85 & 0.98 \\
\hline & Bus route count & $0.02 * * *$ & 4.67 & 1.02 \\
\hline & Average bus wait (min) & $-0.05 * * *$ & -3.22 & 0.95 \\
\hline & Metro stop count & $0.18 * * *$ & 5.79 & 1.20 \\
\hline & Commuter rail stop count & $0.41 * * *$ & 5.18 & 1.51 \\
\hline \multirow[t]{5}{*}{ Destination: } & Distance to downtown $(\mathrm{km})$ & $-0.10 * * *$ & -24.19 & 0.91 \\
\hline & Bus route count & $0.04 * * *$ & 11.62 & 1.04 \\
\hline & Average bus wait (min) & $-0.07 * * *$ & -3.85 & 0.93 \\
\hline & Metro stop count & $0.33 * * *$ & 17.09 & 1.39 \\
\hline & Commuter rail stop count & $0.15 * * *$ & 3.59 & 1.17 \\
\hline \multirow[t]{6}{*}{ Age @ year dummy: } & 20-24 years old in 1998 & $0.80 * * *$ & 5.64 & 2.23 \\
\hline & 25-29 years old in 1998 & $0.38 * * *$ & 2.72 & 1.46 \\
\hline & 30-34 years old in 1998 & $0.40 * * *$ & 2.89 & 1.49 \\
\hline & 35-39 years old in 1998 & $0.35 * *$ & 2.54 & 1.41 \\
\hline & 40-44 years old in 1998 & 0.20 & 1.46 & 1.22 \\
\hline & 45-49 years old in 1998 & 0.16 & 1.17 & 1.18 \\
\hline
\end{tabular}




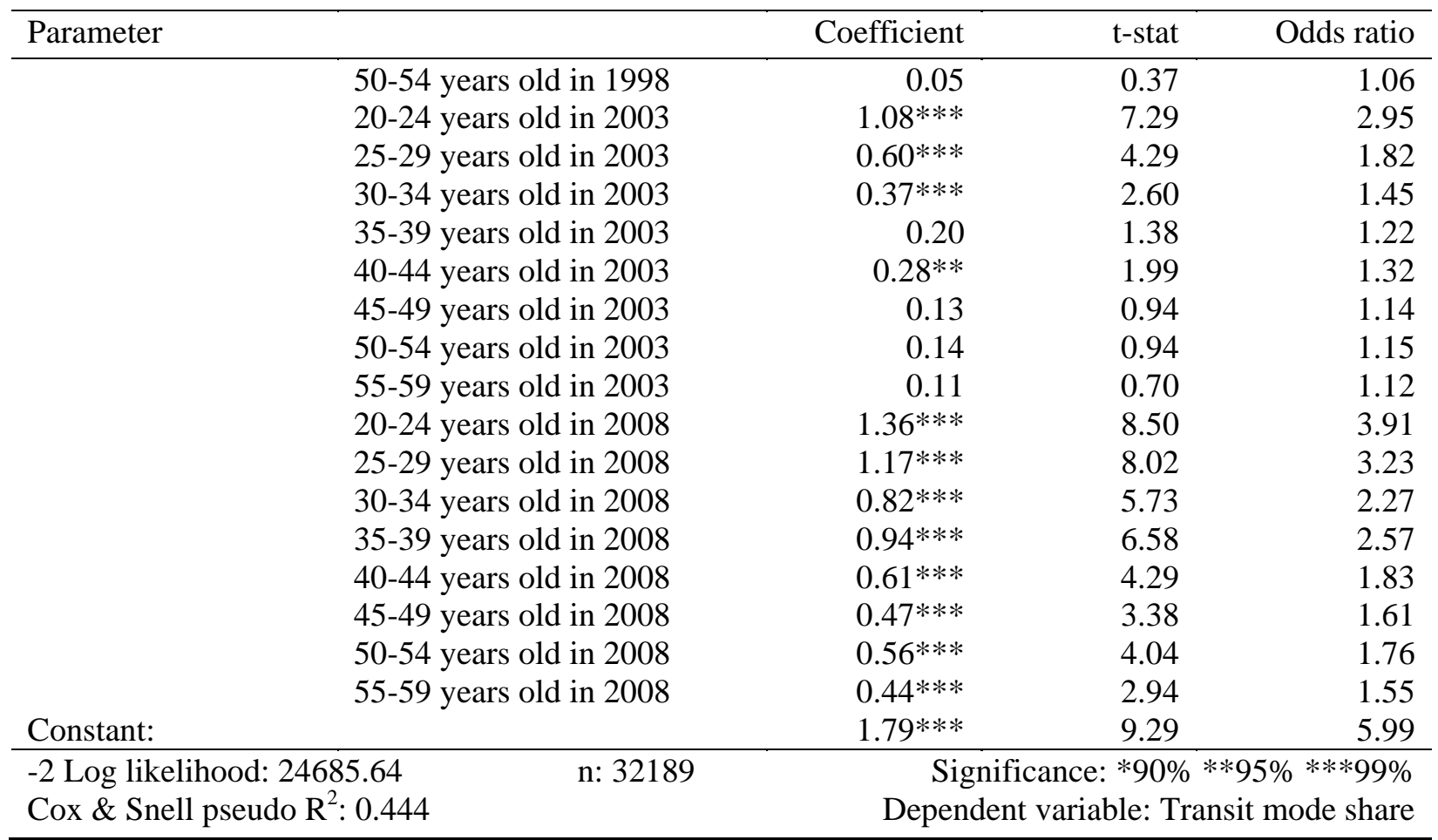

Even after accounting for age, level of service differences and other variables, the odds of school trips being made by transit are over twice as for work trips, a statistically significant impact. Somewhat less dramatic but also statistically significant, females have higher odds of taking transit compared to males and each additional young child or commuter in a household decreases the odds of taking transit by about $20 \%$ or $16 \%$ respectively. Income has a negative and statistically significant effect. A $\$ 1000$ increase corresponds to a $1 \%$ odds decrease in using transit. With the exception of commuter rail stop count, destination variables have greater effects on transit odds than do commensurate home variables, though all are statistically significant. Home commuter rail stop count appears at first to be the most important of all location variables, but with an average count of 0.04 , a unitary increase is essentially the difference between having one or not. Conversely, multiple metro stops (and even more so bus routes) often exist near a location, moderating the apparent impact of each. 
Compared to the 1998 55-59-year-old reference class, the group with the lowest transit use, most other 1998 and 2003 groups in their late 30s and older are not shown to be significantly different at the $90 \%$ confidence level, generally supporting the plateauing use claim made by Grimsrud and El-Geneidy (2013). Age groups up to the early 30s in the same years, and all 2008 groups, show significantly higher transit use. Including the entire sample and comparing each age group/year to that with the lowest use, while providing a convenient overview of control and policy variable effects, does not, however, provide direct answers to the questions of change or stability over time within age groups and birth cohorts.

Table 4 shows survey year effects, as odds ratios, and Cox \& Snell pseudo R-squared values of eight age group-specific logit models and eight birth cohort-specific logit models. Each model uses the same dependent variable (transit use) and control variables as those given in Table 3. Survey year effects for 1998 and 2008 are compared to the 2003 reference group for each age group-specific model. The 2003 age groups are also compared to other years within birth cohorts. Here 1998 20-24-year-olds, 2003 25-29-year-olds and 2008 30-34-year-olds are examined in a single model. The birth cohort aged 20-24 in 2003 is too young in 1998 for inclusion and the 2003 55-59-year-olds are too old in 2008. As with the full model, the odds of choosing transit significantly increase for all age groups and all but the youngest birth cohort (that ages from early to late 20s) from 2003-2008. Significant transit use increase from 1998 to 2003 is limited to early and late 20s age groups, who even after controlling for licensure changes might be particularly affected by improved way-finding and other IT improvements, as well as an emerging sustainability focus in provincial school curricula (Ministère de l'education loisir et sport, 2004) and popular media. 
Table 4: Period effects on commute transit mode share from 16 age or cohort group logit models

\begin{tabular}{|c|c|c|c|c|c|c|c|c|}
\hline \multirow{3}{*}{$\begin{array}{l}\text { Age } \\
\text { group } \\
2003\end{array}$} & \multicolumn{4}{|c|}{ Same age group transit mode share logits } & \multicolumn{4}{|c|}{ Same birth cohort transit mode share logits } \\
\hline & \multicolumn{2}{|c|}{ Odds ratio } & \multirow[b]{2}{*}{$\mathbf{n}$} & \multirow{2}{*}{$\begin{array}{l}\text { Cox \& Snell } \\
\text { pseudo } \mathrm{R}^{2}\end{array}$} & \multicolumn{2}{|c|}{ Odds ratio } & \multirow[b]{2}{*}{$\mathbf{n}$} & \multirow{2}{*}{$\begin{array}{c}\text { Cox \& Snell } \\
\text { pseudo } \mathbf{R}^{2}\end{array}$} \\
\hline & 1998 & 2008 & & & $\begin{array}{c}1998 \\
(-5 y r s)\end{array}$ & $\begin{array}{c}2008 \\
(+5 y r s)\end{array}$ & & \\
\hline $20-24$ & $0.76^{* *}$ & $1.29 * *$ & 3779 & 0.369 & $\mathrm{n} / \mathrm{a}$ & 1.17 & 2481 & 0.41 \\
\hline $25-29$ & $0.78 * *$ & $1.81 * * *$ & 4283 & 0.462 & 1.11 & $1.29 * *$ & 4374 & 0.419 \\
\hline $30-34$ & 1.01 & $1.52^{* * *}$ & 4284 & 0.415 & 1.02 & $1.74^{* * *}$ & 4110 & 0.428 \\
\hline $35-39$ & 1.19 & $2.19 * * *$ & 4457 & 0.443 & $1.22 *$ & $1.54 * * *$ & 4524 & 0.422 \\
\hline $40-44$ & 0.93 & $1.39 * * *$ & 4764 & 0.427 & 1.09 & $1.22 *$ & 4841 & 0.43 \\
\hline $45-49$ & 1.02 & $1.44^{* * *}$ & 4352 & 0.411 & 1.05 & $1.57 * * *$ & 4715 & 0.415 \\
\hline $50-54$ & 0.94 & $1.46^{* * *}$ & 3907 & 0.389 & 1.04 & $1.30 * *$ & 3631 & 0.422 \\
\hline $55-59$ & 0.93 & $1.33^{*}$ & 2363 & 0.428 & 1.04 & $\mathrm{n} / \mathrm{a}$ & 1955 & 0.392 \\
\hline \multicolumn{6}{|c|}{ Dependent variable: Transit mode share } & \multicolumn{3}{|c|}{ Significance: *90\%**95\%***99\% } \\
\hline
\end{tabular}

As Grimsrud and El-Geneidy (2013) supposed, transit mode share decline as people age from their late 20s to early 30s 1998-2003 is insignificant after controlling for other factors - many in this cohort appeared to move to peripheral areas and start families. Unexpectedly, transit decline is also unseen in those aging from their early to late 20s 1998-2003. One further model (not pictured), omitting school trip and children variables, finds the odds of taking transit for those in their early 20s in 1998 to be 1.39 times as high as for 2003 persons in their late 20s, significant at the 99\% confidence level. That changes in commute destination type and family situation affect youths' mode choices, however, is less interesting than is the early onset of within-birth cohort mode choice stability after controlling for these and other changes.

Figure 2 compares observed Island of Montreal transit (versus car) commute mode share to that predicted using full logit model results, as detailed in the Methodology section. The $\mathrm{x}$-axis represents age group center, solid lines represent birth cohorts, and dotted lines tie together data from each survey year. The graphs show very similar line directionality, but the predicted values have more variation than do the actual values, with higher highs and lower lows. Apparently location, service and socioeconomic control variables act unequally between ages and years. 


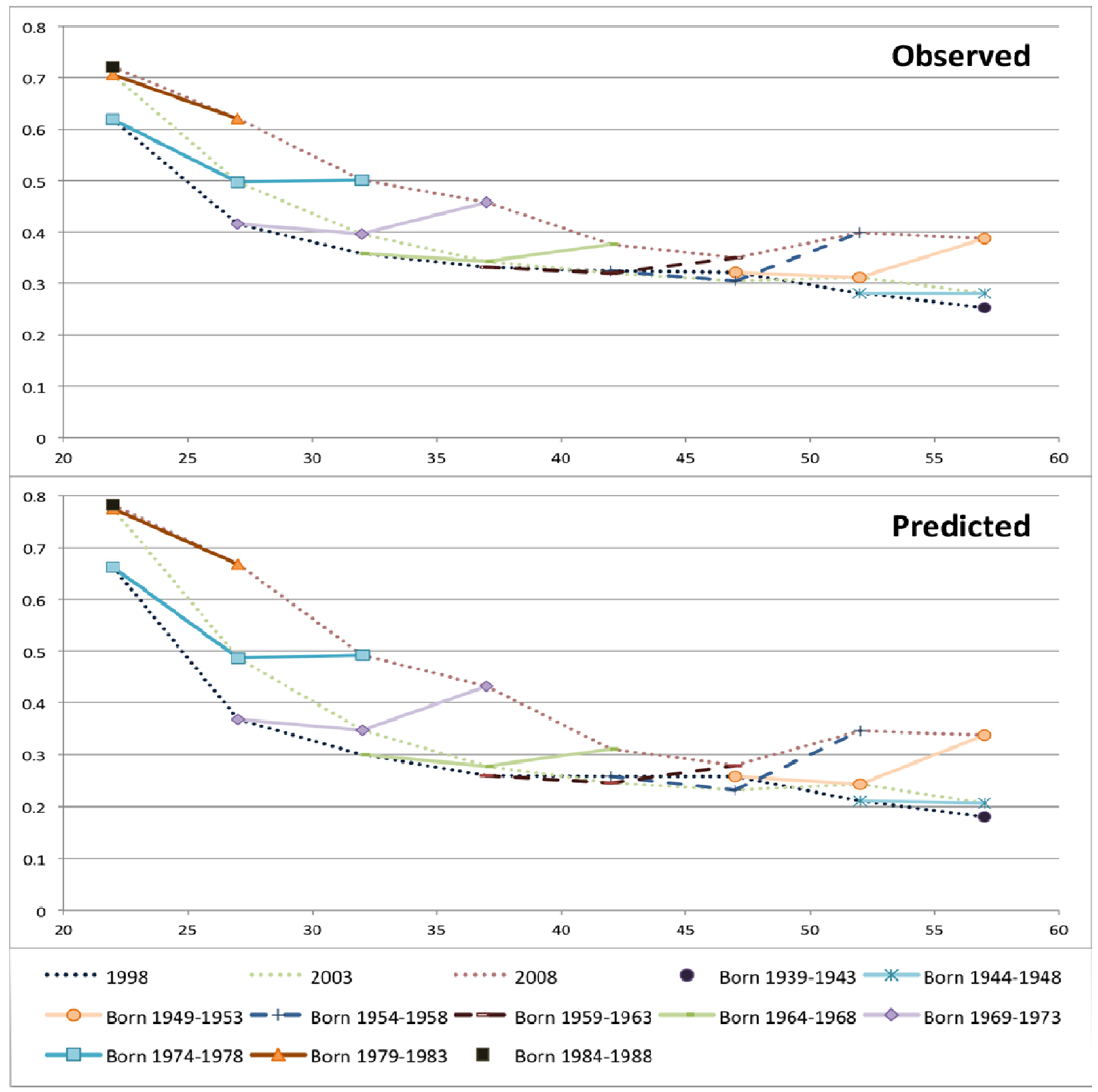

Figure 2: Observed and predicted Island of Montreal transit mode share

Table 5 shows select results from 24 logit models, one for each age group/year, using the same variables as above. Pictured are the odds ratios and significance levels of those variables most consistently significant in the models, and those with strikingly patterned inconsistencies. 
Table 5: Odds ratios for choosing public transport over automobiles: Select covariates from 24 age group/period logit models

\begin{tabular}{|c|c|c|c|c|c|c|c|c|c|c|}
\hline Age & Year & $\begin{array}{l}\text { Female } \\
\text { dummy }\end{array}$ & $\begin{array}{c}\text { School trip } \\
\text { dummy }\end{array}$ & $\begin{array}{c}\text { No license } \\
\text { dummy }\end{array}$ & $\begin{array}{c}\text { Household } \\
\text { Cars / license }\end{array}$ & $\begin{array}{l}\text { Destination to } \\
\text { downtown km }\end{array}$ & $\begin{array}{c}\text { Destination } \\
\text { bus routes }\end{array}$ & $\begin{array}{l}\text { Destination } \\
\text { metro stops } \\
\end{array}$ & $\mathbf{n}$ & $\begin{array}{c}\text { Cox \& Snell } \\
\text { pseudo } \mathbf{R}^{2}\end{array}$ \\
\hline \multirow[t]{3}{*}{$20-24$} & 1998 & $1.60 * * *$ & $2.56^{* * *}$ & $15.06^{* * *}$ & $0.05^{* * *}$ & $0.94 * * *$ & 1.02 & $1.31^{* * *}$ & 1556 & 0.412 \\
\hline & 2003 & 1.16 & $1.86^{* * *}$ & $14.49 * * *$ & $0.06^{* * *}$ & $0.94 * * *$ & 1.02 & $1.62 * * *$ & 1305 & 0.387 \\
\hline & 2008 & 1.13 & $3.16^{* * *}$ & $7.56^{* * *}$ & $0.36 * * *$ & $0.95 * *$ & 1.00 & $1.43^{* * *}$ & 918 & 0.290 \\
\hline \multirow[t]{2}{*}{$25-29$} & 1998 & $1.33^{*}$ & $2.28 * * *$ & $19.10^{* * *}$ & $0.04^{* * *}$ & $0.89 * * *$ & $1.04^{* *}$ & $1.23^{* *}$ & 1571 & 0.457 \\
\hline & 2003 & 1.24 & $1.91 * * *$ & $16.09 * * *$ & $0.04 * * *$ & $0.92 * * *$ & 1.02 & $1.58 * * *$ & 1536 & 0.460 \\
\hline \multirow[t]{3}{*}{$30-34$} & 1998 & 1.19 & $2.24 * * *$ & $19.42 * * *$ & $0.03^{* * *}$ & $0.93^{* * *}$ & $1.05^{* * *}$ & $1.56^{* * *}$ & 1706 & 0.436 \\
\hline & 2003 & $1.31 *$ & $2.03^{* *}$ & $17.52 * * *$ & $0.08 * * *$ & $0.88 * * *$ & 1.03 & $1.28 * *$ & 1296 & 0.418 \\
\hline & 2008 & 1.13 & $2.91^{* * *}$ & $10.81^{* * *}$ & $0.16^{* * *}$ & $0.90^{* * *}$ & $1.03 *$ & $1.54^{* * *}$ & 1282 & 0.387 \\
\hline \multirow[t]{3}{*}{ 35-39 } & 1998 & $1.79 * * *$ & $2.57 * * *$ & $28.25^{* * *}$ & $0.01 * * *$ & $0.91^{* * *}$ & $1.03 *$ & $1.52 * * *$ & 1838 & 0.462 \\
\hline & 2003 & 1.21 & $2.86 * * *$ & $13.10^{* * *}$ & $0.03^{* * *}$ & $0.91 * * *$ & 1.03 & $1.37 * * *$ & 1376 & 0.449 \\
\hline & 2008 & 1.05 & $2.15^{* *}$ & $18.66^{* * *}$ & $0.10 * * *$ & $0.90 * * *$ & $1.06^{* * *}$ & $1.55 * * *$ & 1243 & 0.415 \\
\hline \multirow{2}{*}{$40-44$} & 2003 & $1.42^{* *}$ & 1.60 & $18.51^{* * *}$ & $0.03^{* * *}$ & $0.88^{* * *}$ & $1.04^{* *}$ & $1.41^{* * *}$ & 1497 & 0.440 \\
\hline & 2008 & 1.09 & $3.35 * * *$ & $13.98 * * *$ & $0.10^{* * *}$ & $0.88^{* * *}$ & $1.02 *$ & $1.36^{* * *}$ & 1442 & 0.402 \\
\hline \multirow[t]{3}{*}{$45-49$} & 1998 & $1.73^{* * *}$ & 1.26 & $13.12^{* * *}$ & $0.03^{* * *}$ & $0.90 * * *$ & $1.06^{* * *}$ & $1.35^{* * *}$ & 1459 & 0.433 \\
\hline & 2003 & 1.12 & 1.78 & $10.71^{* * *}$ & $0.03^{* * *}$ & $0.90 * * *$ & $1.05^{* * *}$ & $1.37 * * *$ & 1387 & 0.416 \\
\hline & 2008 & 1.06 & $2.74 *$ & $21.12^{* * *}$ & $0.12^{* * *}$ & $0.90 * * *$ & $1.04 * * *$ & $1.70 * * *$ & 1506 & 0.405 \\
\hline \multirow[t]{3}{*}{$50-54$} & 1998 & $2.43^{* * *}$ & $4.71^{*}$ & $8.02 * * *$ & $0.06 * * *$ & $0.89 * * *$ & $1.06 * * *$ & $1.18^{*}$ & 1219 & 0.376 \\
\hline & 2003 & $1.46^{* *}$ & $4.40 *$ & $14.22^{* * *}$ & $0.04 * * *$ & $0.90 * * *$ & $1.03^{*}$ & $1.38 * * *$ & 1185 & 0.396 \\
\hline & 2008 & $1.30 *$ & 2.00 & $17.88^{* * *}$ & $0.15^{* * *}$ & $0.87^{* * *}$ & $1.05^{* * *}$ & $1.26^{* * *}$ & 1503 & 0.394 \\
\hline \multirow[t]{3}{*}{ 55-59 } & 1998 & $1.79 * *$ & 0.62 & $11.04^{* * *}$ & $0.04 * * *$ & $0.85 * * *$ & $1.06^{*}$ & 1.15 & 640 & 0.384 \\
\hline & 2003 & $1.61 *$ & 3.71 & $20.87^{* * *}$ & $0.02 * * *$ & $0.91^{* * *}$ & $1.07 * * *$ & $1.74^{* * *}$ & 736 & 0.438 \\
\hline & 2008 & 1.21 & 0.75 & $13.82^{* * *}$ & $0.05^{* * *}$ & $0.90^{* * *}$ & $1.05^{* *}$ & $1.45^{* * *}$ & 987 & 0.442 \\
\hline
\end{tabular}


Female gender appears to increase odds of taking transit in all cases, but this is becoming less significant over time, from nearly all age groups in 1998 to only 50-54-year-olds in 2008 (and there only at the $90 \%$ confidence level). School commutes, as opposed to work, have a stronger and more stable effect, but are rarely significant for older groups (probably due to small subsamples). Driver's licensure is highly important for all age groups in all years. Household cars per license, while similarly consistent in significance and always showing a strong negative association with transit use, clearly diminishes in importance, especially between 2003 and 2008. For most age groups, the effect of an additional car per licensed driver drops several fold during this interval - people with cars are not using them to get to work and/or carpooling is increasing.

With the exception of commuter rail station count (not pictured), destination variables were more consistently significant than their origin counterparts. Aside from automobile access-related variables, the only other variable always significant at the $95 \%$ confidence level is distance from destination to downtown, which seems to be somewhat less important for the youngest age group but otherwise shows no compelling pattern. Number of metro stops near destination, almost always significant, too shows no striking trends. Parking data was not available for this study, but it seems fair to assume that parking pricing and availability would correspond in some way spatially to density and competition. That the importance of these two variables does not spike in 2008 suggests that possible changes in parking policy, as influential as it can be to mode share generally (De Witte et al., 2013) and in Montreal, would explain little of the 2008 transit use growth seen across all age groups and most birth cohorts. Nor, recalling summary statistics (Table 2), would gradual location and service level changes. That is not to say that local agencies are not making valuable improvements to service, however - the number of bus routes 
near destinations is consistently significant for older riders, and has been increasing (if gradually) between 1998 and 2008.

\section{6 - DISCUSSION AND CONCLUSIONS}

Transit mode share is increasing among young age groups, which is not explained by tested socioeconomic, household composition, level of service, automobile access, and location variables. It is also remarkably consistent over the life-course taking these factors into account. After applying this variety of controls, transit mode share is up substantially for commuters in their 20s and there is no change within any birth cohorts between 1998 and 2003 significant at the 95\% confidence level. It is clear from summary statistics and unsurprising that the youngest birth cohorts use transit less as they age, but this happens concurrently with other significant changes, such as school versus work destination type, presence of young children, and access to transport alternatives. The recently elevated youth transit commute mode share rates, factorcontrolled mode consistency within birth cohorts, and early-life concentration of changes in many important variables (Beige, 2008; Thakuriah et al., 2009), collectively suggest increases in overall future transit use or demand.

Regarding the population-wide 2008 transit use increase, this paper rules out sudden substantial changes in various transit service level indicators or home and destination locations as main explanatory factors, and it suggests that any parking policy changes have not had a pronounced 2008 effect. It thus supports the notion that 2008 transit mode share gains observed in older cohorts are likely temporary responses to a shocking gasoline price change, rather than a sign of new lasting behaviors in mature commuters. It cannot prove this point, however, as it cannot disentangle effects of known (and unknown) spatially invariant factors specific to the 2008 
survey, notably the gasoline price spike and improved information technology. Future work with existing surveys might be able to address this to some degree, if survey interview date information can be made available, although there might be some attribution difficulties associated with timing, as long-term fuel-price-to-use elasticities tend to be higher than shortterm (Goodwin, Dargay, \& Hanly, 2004). Another survey is to be conducted in autumn 2013, the results of which can address the 2008 question and validate or challenge this paper's findings.

Results herein support Grimsrud and El-Geneidy’s (2013) novel but limited summary statisticsbased findings that high recent youth transit use is likely to lead to high overall use, declining some with age but to higher rates than previous generations'. Unlike the aforementioned study, the current study controlled for a wide variety of covariates, some of which lacked historical data outside the Island of Montreal, so said surrounding area had to be excluded from analysis. This omission might also have reduced the magnitude of observed and expected change, as the island already has very high transit ridership. However, being able to distinguish effects of changing contextual factors both strengthens the claim and allows inspection of such elements. The previous work noted some changes to conditions but it did not attempt to measure their impacts, and some of these might have useful policy or research implications.

Measured factors that appear to have had some of the largest effects on mode share trends include declining driver's licensure rates, declining importance of vehicle ownership, growing numbers of young people in school, decreasing distances between destinations and downtown and improved destination metro access. Municipal policies facilitating increased employment density in central transit-, especially metro-friendly locations, might bring further commute trip 
transit share gains. The declining, if always substantial, importance of automobile access 20032008 and the somewhat stable access rates themselves suggest that a growing number of kept automobiles are not used for commutes. They presumably are kept with reason. Some of the many 2008 transit riders might see the situation as temporary and maintain vehicles for future use. Also, trends in mode share for shopping and other types of trips, as well as relevant factors and policies, might differ from those for peak hour commutes.

Graduated licensing, primarily intended to increase road safety, also requires increased effort and time to qualify for a license, and many who might eventually qualify do not attain licenses when they are able. Particularly for men, drops to licensure rates are found to hold over time; as such graduated licensing appears to be a powerful tool for influencing mode shares and could perhaps be made more stringent for increased effect given sufficient transit alternatives. This gender discrepancy merits further research, as might the diminishing significance gender appears to have on transit mode choice, even among groups not yet noticeably affected by graduated licensing.

Also worth additional investigation, school trips are much more likely than work trips to be by transit for individuals of the same age. The increasing numbers of young people pursuing higher education is not the sole determinant of increased youth use rates, but the eventual switch from school to work with age does involve a substantial reduction in transit use, even after accounting for possible service level and other differences. It is unclear how this relates to changes in income, which was only crudely accounted for herein (by census tract average), opportunities to productively use time on transit, item transport needs, company culture, or other factors. One 
known difference between young workers and young students is transit price, with students 25 and younger eligible for reduced rates. STM might consider including young workers, to improve youth ridership retention through this important life-course transition, and recover income through higher ridership down the road.

Other cities have different circumstances, particularly in terms of population density and extent of existing infrastructure, but many have similar repeated cross-sectional transport survey datasets that can and perhaps should be examined by cohort, as well as age group and other factors. Some have robust panel data that might provide additional insights. Given that increases seen among youths (Davis et al., 2012; Kuhnimhof et al., 2012), and lifecycle patterns and habits (Simma \& Axhausen, 2003) are not unique to Montreal, comparable studies elsewhere might similarly find reason to expect increased future transit demand and to prioritize maintaining high transit use as current and future young people age.

\section{7 - ACKNOWLEDGEMENTS}

Thanks to Daniel Bergeron and AMT for access to Montreal Origin-Destination survey data analyzed in this paper (2003 and 2008), to Mr. Pierre Tremblay from the Quebec Ministry of transport for providing the 1998 Montreal Origin-Destination survey, and to Sébastien Gagné from STM for bus schedule access. We would also like to acknowledge the members and affiliated researchers of TRAM research group, especially Ehab Diab and Vincent Chakour for technical advice and Naveen Eluru for helpful feedback. 


\section{8 - REFERENCES}

Agence Metropolitaine de Transport (AMT). (2012a). AMT - origin-destination survey Retrieved 20 January, 2012, from http://www.amt.qc.ca/corp_template.aspx?id=686\&LangType=1033

Agence Metropolitaine de Transport (AMT). (2012b). Programme Triennal D'immobilisations 2012/2013/2014 $\quad$ Retrieved 22 February, 2013, from http://www.amt.qc.ca/uploadedfiles/amt/site_corpo/nouvelles_et_publications/PTI_2012-1314.pdf

Beige, S. (2008). Long-term and mid-term mobility decisions during the life course. (Dissertation), Institut für Verkehrsplanung und Transportsysteme, Zürich.

Bush, S. (2005). Forecasting 65+ travel: An integration of cohort analysis and travel demand modeling. Paper presented at the Annual meeting of the Transportation Research Board. http://18.7.29.232/bitstream/handle/1721.1/29941/52770123.pdf?sequence=1

Cervero, R., \& Kockelman, K. (1997). Travel demand and the 3D's: Density, diversity, and design. Transportation Research Part D 2(3), 199-219.

Chen, C., Gong, H., \& Paaswell, R. (2008). Role of the built environment on mode choice decisions: additional evidence on the impact of density. Transportation, 35(3), 285-299.

Collin, J., Dagenais, M., \& Poitras, C. (2003). From city to city-region: Historical perspective on the contentious definition of the Montréal Metropolitan area. Canadian Journal of Urban Research, 12(1), 16-34.

Dargay, J. (2007). The effect of prices and income on car travel in the UK. Transportation Research Part A, 41(10), 949-960.

Dargay, J., \& Hanly, M. (2003). Travel to work: an investigation based on the British household panel survey Paper presented at the NECTAR Conference No. 7, Umea ${ }^{\circ}$, Sweden.

Dargay, J., \& Hanly, M. (2007). Volatility of car ownership, commuting mode and time in the UK. Transportation Research: Part A, 41(10), 934-948.

Davis, B., Dutzik, T., \& Baxandall, P. (2012). Transportation and the new generation: Why young people are driving less and what it means for transportation policy: Frontier Group, U.S. PIRG Education Fund.

De Witte, A., Hollevoet, J., Dobruszkes, F., Hubert, M., \& Macharis, C. (2013). Linking modal choice to motility: A comprehensive review. Transportation Research Part A, 49, 329-341.

Diab, E., \& El-Geneidy, A. (2012). Understanding the impacts of a combination of service improvement strategies on bus running time and passenger's perception. Transportation Research: Part A, 46(3), 614-625.

Dickens, M. (2012). Public transportation ridership report: Fourth quarter 2011 (pp. 1-31). Washington: American Public Transportation Association.

El-Geneidy, A., Tetreault, P., \& Surprenant-Legault, J. (2010). Pedestrian access to transit: Identifying redundancies and gaps using a variable service area analysis. Paper presented at the 89th Transportation Research Board Annual Meeting, Washington D.C., USA.

Fan, W., \& Machemehl, R. (2009). Do transit users just wait for buses or wait with strategies? Transportation Research Record(2111), 169-176.

Goodwin, P., Dargay, J., \& Hanly, M. (2004). Elasticities of road traffic and fuel consumption with respect to price and income: A review. Transport Reviews, 24(3), 275-292.

Grimsrud, M., \& El-Geneidy, A. (2013). Transit to eternal youth: Lifecycle and generational trends in Greater Montreal public transport mode share. Transportation. doi: 10.1007/s11116-013-9454-9

Hall, R. (2001). Passenger waiting time and information acquisition using automatic vehicle location for verification. Transportation Planning and Technology, 24, 249-269.

Kim, S., \& Ufarsson, G. (2008). Curbing automobile use for sustainable transportation: analysis of mode choice on short home-baesd trips. Transportation, 35(6), 723-737.

Knoblauch, R., Pietrucha, M., \& Nizburg, M. (1996). Field studies of pedestrian walking speed and startup time. Transportation Research Record(1538), 27-38. 
Kuhnimhof, T., Buehler, R., Wirtz, M., \& Kalinowska, D. (2012). Travel trends among young adults in Germany: increasing multimodality and declining car use for men. Journal of Transport Geography, 24, 443-450.

Levinson, D., \& El-Geneidy, A. (2009). The minimum circuity frontier and the journey to work. Regional Science and Urban Economics, 39, 732-738.

Limtanakool, N., \& Dijst, M. (2006). The influence of socioeconomic characteristics, land use and travel time in consideration on mod choice for medium- and longer-distance trips. Journal of Transport Geography 14(5), 327-341.

Mason, K., Mason, W., Winsborough, H., \& Poole, W. (1973). Some methodological issues in cohort analysis of archival data. American Sociological Review, 38, 843-861.

Matas, A., \& Raymond, J. (2008). Changes in the structure of car ownership in Spain. Transportation Research: Part A, 42(1), 187-202.

Ministère de l'education loisir et sport. (2004). Reform du curriculum: Les disciplines retenues dans le curriculum et leur distribution dans la grille-matière Retrieved October 12, 2012, from http://www.mels.gouv.qc.ca/reforme/curricu/ecole04.htm

Nolan, A. (2010). A dynamic analysis of household car ownership. Transportation Research: Part A, 44(6), 446-455.

O'Brien, R. (2000). Age period cohort characteristic models. Social Science Research, 29, 123-139.

Regie de l'energie Quebec. (2009). Évolution des prix de détail de l'essence ordinaire en 2008 - Région de Montréal. Quebec: Regie de l'energie Quebec.

Shalaby, A. (1998). Investigating the role of relative level-of-service characteristics in explaining mode split for the work trip. Transportation and Planning Technology, 22(2), 125-148.

Simma, A., \& Axhausen, K. (2003). Commitments and modal usage: Analysis of German and Dutch panels. Transportation Research Record(1854), 22-31.

Simpson, H. (2003). The evolution and effectiveness of graduated licensing. Journal of Safety Research, 34(1), 25-34.

Societe de transport de Montreal (STM). (2012). Important dates in STM's history Retrieved May 16, 2012, from http://www.stm.info/english/en-bref/a-dates.htm

Societe de transport de Montreal (STM). (2013). Bus schedules: September 1998, 2003, 2008.

Statistics Canada. (2010). 2006 census: census trends - selected trend data for Montreal (CMA), 2006, 2001 and 1996 censuses Retrieved April 13, 2012, from http://www12.statcan.ca/censusrecensement/2006/dp-pd/92-596/P1-

2.cfm?Lang=eng\&T $=$ CMA\&PRCODE $=24 \& G E O C O D E=462 \& G E O L V L=C M A \& T I D=0$

Statistics Canada. (2012a). CANSIM table 282-0110: Labour force survey estimates (LFS), by census metropolitan area based on 2006 census boundaries, sex and age group, from http://www5.statcan.gc.ca/cansim/a05?lang=eng\&id=2820110

Statistics Canada. (2012b). CANSIM table 326-0020 consumer price index, 2009 basket, from http://www5.statcan.gc.ca/cansim/a05?lang=eng\&id=3260020

Statistics Canada. (2012c). CHASS Canadian Census Analyser: Profile of Census Tracts Retrieved February 25, 2013, from http://dc.chass.utoronto.ca/census/ct.html

Statistics Canada. (2013). Census Profile: Montreal Retrieved February 12, 2013

Sweet, M., \& Chen, M. (2011). Does regional travel time unreliability influence mode choice? Transportation, 38(4), 635-642.

Thakuriah, P., Menchu, S., \& Tang, L. (2010). Car ownership among young adults: Generational and period-specific perspective. Transportation Research Record(2156), 1-8.

Thakuriah, P., Tang, L., \& Menchu, S. (2009). Young women's transportation and labor market experiences. Paper presented at the 4th TRB international conference on women's issues in transportation, Irvine.

Thogersen, J. (2006). Understanding repetitive travel mode choices in a stable context: A panel study approach. Transportation Research Part A, 40(8), 621-638. 